\title{
Effect of alternate day fasting on markers of bone metabolism: An exploratory analysis of a 6-month randomized controlled trial
}

\author{
Adrienne Barnosky ${ }^{\mathrm{a}, \mathrm{b}}$, Cynthia M. Kroeger ${ }^{\mathrm{a}, \mathrm{c}}$, John F. Trepanowski ${ }^{\mathrm{a}, \mathrm{d}}$, Monica C. Klempel ${ }^{\mathrm{a}}$, \\ Surabhi Bhutani ${ }^{a}$, Kristin K. Hoddy ${ }^{\mathrm{a}}$, Kelsey Gabel ${ }^{\mathrm{a}}$, Sue A. Shapses ${ }^{\mathrm{e}}$ and Krista A. Varady,* \\ ${ }^{a}$ Department of Kinesiology and Nutrition, University of Illinois at Chicago, Chicago, IL, USA \\ ${ }^{\mathrm{b}}$ Endocrinology, Diabetes and Metabolism, Wheaton Franciscan Healthcare, Ascension, Wauwatosa, WI, USA \\ ${ }^{\mathrm{c}}$ Nutrition Obesity Research Center, University of Alabama at Birmingham, Birmingham, AL, USA \\ ${ }^{\mathrm{d}}$ Stanford Prevention Research Center, Stanford University, Stanford, CA, USA \\ ${ }^{\mathrm{e}}$ Department of Nutritional Sciences, Rutgers University, New Brunswick, NJ, USA
}

\begin{abstract}
.
BACKGROUND: Alternate day fasting (ADF) is a novel diet therapy that reduces body weight, but its effect on bone health remains unknown.

OBJECTIVE: This study examined the impact of ADF versus traditional daily calorie restriction (CR) on markers of bone metabolism in a 6-month randomized controlled trial.

METHODS: Overweight and obese subjects $(n=100)$ were randomized to 1 of 3 groups for 6 months: 1) ADF (25\% energy intake fast day, alternated with $125 \%$ intake feast day; 2$)$ CR (75\% intake every day); or 3) control (usual intake every day). RESULTS: Body weight decreased similarly $(P<0.001)$ by ADF $(-7.8 \pm 1.2 \%)$ and CR $(-8.8 \pm 1.5 \%)$, relative to controls by month 6 . Lean mass, total body bone mineral content and total body bone mineral density remained unchanged in all groups. Circulating osteocalcin, bone alkaline phosphatase, and C-terminal telopeptide type I collagen (CTX) did not change in any group. IGF-1 increased $(P<0.01)$ in the CR group, with no change in the ADF or control group. When the data were sub-analyzed according to menopausal status, there were no differences between premenopausal or postmenopausal women for any marker of bone metabolism.

CONCLUSION: These findings suggest that 6 months of ADF does not have any deleterious impact on markers of bone metabolism in obese adults with moderate weight loss.
\end{abstract}

Keywords: Alternate day fasting, calorie restriction, bone metabolism, bone mineral content, bone mineral density, obese adults

\section{Introduction}

Daily calorie restriction (CR) regimens are some of the most widely used diet strategies for weight loss [1]. These regimens involve reducing energy intake by

\footnotetext{
${ }^{*}$ Corresponding author: Krista Varady, PhD, Associate Professor of Nutrition, Department of Kinesiology and Nutrition, University of Illinois at Chicago, 1919 West Taylor Street, Room 532, Chicago, IL, 60612, USA. Tel.: +1 312996 7897; E-mail: varady@uic.edu.
}

15-40\% of needs each day [1]. While CR has resulted in successful weight loss for some individuals, adherence can be challenging because of the need for daily calorie counting. Alternate day fasting (ADF) may be an effective alternative for weight loss, because this diet only requires calorie counting every other day [2, $3]$. ADF generally allows for $25 \%$ of energy needs ( $\sim 500 \mathrm{kcal})$ to be consumed on the "fast day", and ad libitum food consumption on alternating "feast days". Previous trials of ADF generally report reductions 
in body weight of 3-8\% after 2-3 months, accompanied by decreases in triglycerides, blood pressure, and increases in HDL cholesterol levels [3-10].

Fluctuations in body weight play an important role in bone health $[11,12]$. Data from recent human trials show that weight loss by daily CR can result in bone loss [13-16], but not always [17-20]. Daily energy restriction regimens may also result in unfavourable changes in markers of bone metabolism. For instance, some controlled trials of $\mathrm{CR}$ have demonstrated decreases in markers of bone formation, including osteocalcin [14], bone alkaline phosphatase [15, 17], accompanied by increases in markers of bone resorption, i.e. C-terminal telopeptide type I collagen (CTX) $[14,15,17]$. Whether weight loss by ADF produces similar deleterious modulations in markers of bone metabolism is an important question that has yet to be addressed. Accordingly, the goal of this study was to compare the effects of ADF to that of daily $\mathrm{CR}$ on markers of bone metabolism in a 6-month randomized controlled trial. We also performed a subanalysis to examine if changes in these markers are influenced by menopausal status.

\subsection{Subjects}

This is a secondary analysis of a study that examined the impact of these diets on body weight [21]. Men and women $(n=100)$ aged $18-65$ years with a BMI of 25 to $39.9 \mathrm{~kg} / \mathrm{m}^{2}$ were recruited from the University of Illinois at Chicago campus and surrounding community by flyers, as reported previously [21]. Individuals were excluded if they had a history of cardiovascular disease, diabetes mellitus, were taking weight loss medications, were not weight stable for 3 months prior to study initiation, were perimenopausal, pregnant, or smokers. All participants provided informed consent to participate in this study. The protocol was approved by the Office for the Protection of Research Subjects at the University of Illinois, Chicago.

\subsection{Experimental design}

Subjects were randomized by a stratified random sample (based on age, sex, and BMI) to 1 of 3 groups for 6-months: 1) $\mathrm{ADF}(n=34)$; 2) $\mathrm{CR}(n=35)$; or 3) control $(n=31)$ (Fig. 1). The 6-month trial was divided into a 3-month "controlled feeding period", followed by a 3-month "self-selected feeding period" (Fig. 2).

\subsection{Study diets}

During the "controlled feeding period" (Fig. 2), $\mathrm{ADF}$ and $\mathrm{CR}$ groups were provided with all meals. Diets were structured as a 3-day rotating menu with the following macronutrient composition: $30 \% \mathrm{kcal}$ from fat, $15 \%$ from protein, and 55\% from carbohydrates [22]. Total energy expenditure at baseline was calculated by the doubly labeled water technique, as previously described [21, 23], which informed calorie targets for each subject. Subjects in the ADF group consumed $25 \%$ of energy needs on each fast day (between $12.00 \mathrm{pm}-2.00 \mathrm{pm}$ ) and $125 \%$ of energy needs on the feast day. Subjects in the CR group consumed $75 \%$ of their energy needs every day. All meals were consumed outside of the research center. During the "self-selected feeding period" (Fig. 2), $\mathrm{ADF}$ and $\mathrm{CR}$ subjects were no longer provided with meals. Instead, subjects received one-on-one weekly dietary counselling to learn how to continue with their intervention assignments on their own. Briefly, subjects were provided with their individualized daily calorie targets and taught how to monitor calories, portion sizes, and macronutrient composition according to American Heart Association guidelines [22].

\subsection{Control group protocol}

Controls were asked to maintain their body weight by continuing their usual eating and activity habits throughout the trial. Control subjects did not receive any food or dietary counselling, but visited the research center at the same frequency as the intervention groups to control for any investigator-interaction bias.

\subsection{Dietary intake and physical activity}

Dietary intake was assessed at baseline and month 6 by a 7-day food record, and analyzed using Nutritionist Pro software (Axxya Systems LLC) as described previously [21]. Calcium and vitamin D supplements were permitted during the study, but were not recorded in the food records. Thus, only dietary calcium and vitamin D intake is reported in the results. As for physical activity, all groups were asked to maintain their level of activity throughout the trial. Maintenance of activity was assessed by a validated [24] pattern recognition monitor (Sense Wear Mini, Bodymedia, Pittsburg, PA). Subjects wore the 


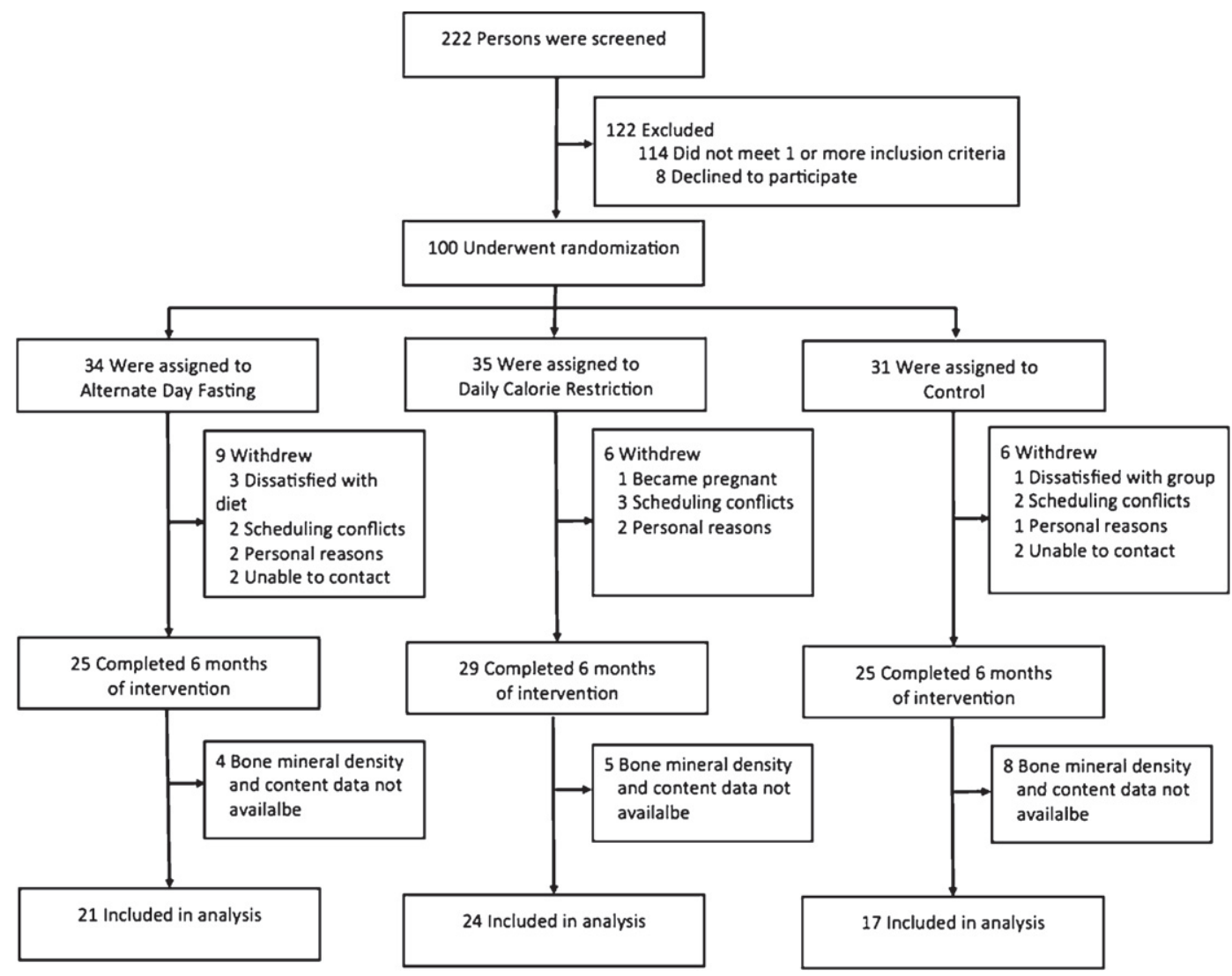

Fig. 1. Study flow chart.

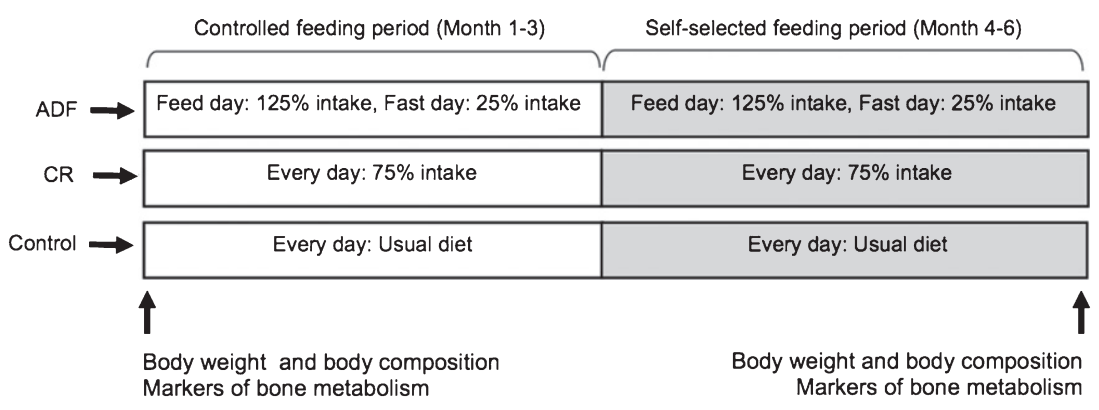

Fig. 2. Experimental design.

monitor on their upper arm for 7 days at baseline and the end of month 6 .

\subsection{Body weight and body composition}

Body weight was measured to the nearest $0.1 \mathrm{~kg}$ at baseline and month 6 after an overnight fast in a hospital gown by a digital scale (HBF-500, Omron, Bannockburn, IL). Fat mass, lean mass, total body bone mineral content, and total body bone mineral density were assessed in the fasted state at baseline and month 6 by dual energy X-ray absorptiometry (DXA; QDR 4500W, Hologic, Arlington, MA).

\subsection{Circulating markers of bone metabolism}

Blood samples were obtained following a 12hour fast at baseline and month 6. All participants were asked to avoid exercise, alcohol, and coffee for $24 \mathrm{~h}$ before each visit. Samples were centrifuged for $10 \mathrm{~min}$ at $520 \mathrm{I} \mathrm{g}$ at $4{ }^{\circ} \mathrm{C}$ to separate plasma from red cells and were stored at $-80^{\circ} \mathrm{C}$ until analyzed. 
Table 1

Baseline characteristics of the subjects who completed the study

\begin{tabular}{lcccc}
\hline & $\begin{array}{c}\text { Alternate day } \\
\text { fasting }\end{array}$ & $\begin{array}{c}\text { Daily Calorie } \\
\text { Restriction }\end{array}$ & Control & $P$-value \\
\hline $\mathrm{n}$ & 21 & 24 & 17 & \\
Age $(\mathrm{y})$ & $44 \pm 2$ & $44 \pm 2$ & $40 \pm 3$ & 0.37 \\
Sex $(\mathrm{F} / \mathrm{M})$ & $19 / 2$ & $20 / 4$ & $15 / 2$ & 0.53 \\
Ethnicity & & & & \\
$\quad$ African American & 14 & 14 & 8 & 0.77 \\
$\quad$ Caucasian & 5 & 9 & 0 & 0.40 \\
$\quad$ Hispanic & 2 & 0 & 0 & 0.59 \\
$\quad$ Asian & $92 \pm 3$ & $96 \pm 3$ & $87 \pm 3$ & 0.72 \\
Body weight $(\mathrm{kg})$ & $164 \pm 2$ & $167 \pm 2$ & $163 \pm 2$ & 0.13 \\
Height $(\mathrm{cm})$ & $34 \pm 1$ & $34 \pm 1$ & $32 \pm 1$ & 0.34 \\
Body mass index $\left(\mathrm{kg} / \mathrm{m}^{2}\right)$ & $37 \pm 1$ & $38 \pm 1$ & $33 \pm 2$ & 0.24 \\
Fat mass $(\mathrm{kg})$ & $53 \pm 2$ & $56 \pm 2$ & $52 \pm 2$ & 0.37 \\
Lean mass $(\mathrm{kg})$ & $2402 \pm 85$ & $2405 \pm 96$ & $2246 \pm 106$ & 0.45 \\
Total body BMC $(\mathrm{g})$ & $1.23 \pm 0.02$ & $1.19 \pm 0.03$ & $1.17 \pm 0.03$ & 0.27 \\
Total body BMD $\left(\mathrm{g} / \mathrm{cm}^{2}\right)$ & & & & \\
\hline
\end{tabular}

Mean \pm SEM. F: Female, M: Male, BMC: Bone mineral content, BMD: Bone mineral density. $P$-values reported for comparison of baseline variables between the alternate day fasting, daily calorie restriction and control groups (One-way ANOVA).

Markers of bone metabolism were measured by ELISA: osteocalcin (R\&D Systems, Minneapolis, MN); bone alkaline phosphatase and CTX (MyBioSource, San Diego, CA). Insulin-like growth factor-1 (IGF-1) was also assessed by ELISA (R\&D Systems, Minneapolis, MN).

\subsection{Statistics}

Results are presented as means \pm standard error of the mean (SEM). Normality was assessed by the Kolmogorov-Smirnov test, and no variables were found to be not normal. One-way ANOVA was used to test the differences among groups at baseline. Repeated measures ANOVA was used to evaluate main effects of diet, time, and diet $\times$ time effects. When main effects were detected, pairwise comparisons using the least significant difference test were applied. A $P$-value of less than 0.05 was used for statistical significance. Data were analyzed by using SPSS software (v.21, SPSS Inc., Chicago, IL).

\section{Results}

\subsection{Subject flow through the trial}

A total of $n=100$ subjects were randomized to the three intervention groups (ADF $n=34, \mathrm{CR} n=35$, control $n=31$ ) (Fig. 1). After 6 months, $n=9$ dropped out of the ADF group, $n=6$ dropped out of the CR group, and $n=6$ dropped out of the control group. Reasons for subject withdrawals included: dissatisfaction with study diets, scheduling conflicts, and personal reasons. The number of completers in each group was as follows: $\mathrm{ADF} n=25$; $\mathrm{CR} n=29$; and control $n=25$. Of these completers, bone mineral density and content data were available for $n=21$ $\mathrm{ADF}, n=24 \mathrm{CR}$, and $n=17$ control subjects. Consequently, only these subjects were used for the purposes of the present study.

\subsection{Baseline characteristics}

Baseline characteristics did not differ among the groups (Table 1). A comparison between premenopausal and postmenopausal women's baseline characteristics was also performed. As expected, postmenopausal women were older than premenopausal women $(56 \pm 5 \mathrm{y}$ versus $37 \pm 6 \mathrm{y}$; $P<0.05$ ); otherwise the two subgroups had similar baseline characteristics.

\subsection{Body weight and body composition}

In the analysis of all participants (Fig. 3A), body weight decreased significantly $(P<0.001)$ in the ADF $(-7.8 \pm 1.2 \%)$ and $\mathrm{CR}$ group $(-8.8 \pm 1.5 \%)$, relative to controls, by month 6 , with no difference between 

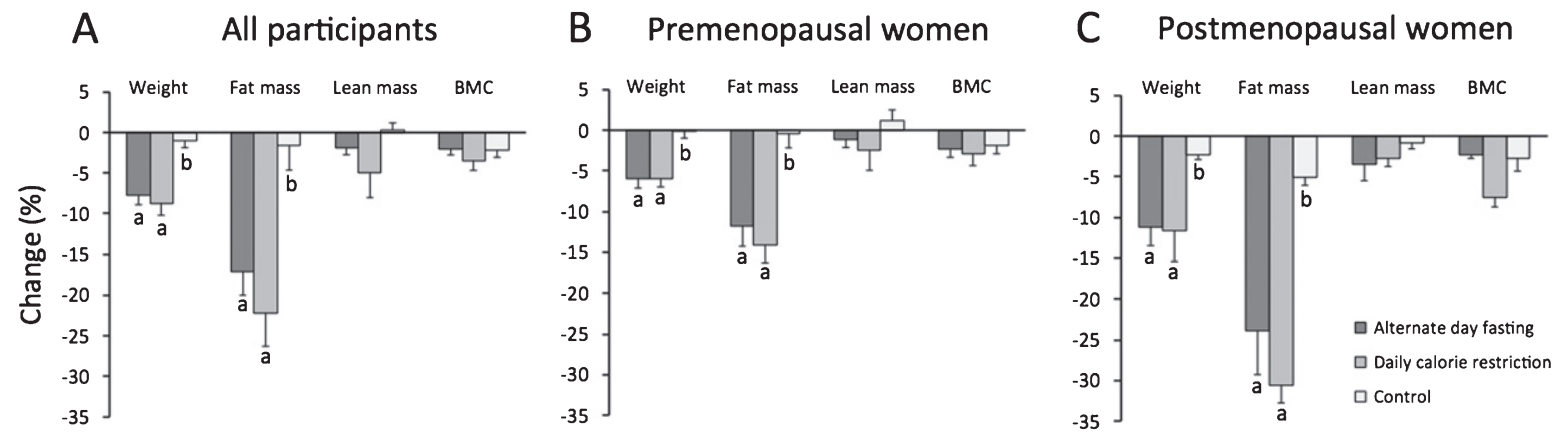

Fig. 3. Change in body weight and body composition after 6 months. Mean \pm SEM. BMC: Bone mineral content. Means with different superscript values are significantly different $(P<0.01)$ for each body composition parameter. A. All participants: Body weight and fat mass decreased significantly $(P<0.01)$ in the ADF and CR groups, relative to controls. Lean mass and BMC remained unchanged in all groups. B. Premenopausal women: Body weight and fat mass decreased significantly $(P<0.01)$ in the ADF and CR groups, relative to controls. Lean mass and BMC remained unchanged in all groups. C. Postmenopausal women: Body weight and fat mass decreased significantly $(P<0.01)$ in the ADF and $\mathrm{CR}$ groups, relative to controls. Lean mass and BMC remained unchanged in all groups. Postmenopausal women lost more $(P<0.05)$ body weight and fat mass relative to premenopausal women in the same intervention group.

ADF and CR. Fat mass was reduced $(P<0.01)$ by $\mathrm{ADF}$ and $\mathrm{CR}$, versus controls, with no differences between ADF and CR. Lean mass and total body bone mineral content did not change in any group. Total body bone mineral density did not change over 6 months in the ADF group (baseline: $1.23 \pm 0.02 \mathrm{~g} / \mathrm{cm}^{2}$; month $\left.6: 1.24 \pm 0.02 \mathrm{~g} / \mathrm{cm}^{2}\right)$ or CR group (baseline: $1.19 \pm 0.03 \mathrm{~g} / \mathrm{cm}^{2}$; month $6: 1.20 \pm 0.03 \mathrm{~g} / \mathrm{cm}^{2}$ ), relative to controls (baseline: $1.17 \pm 0.03 \mathrm{~g} / \mathrm{cm}^{2}$; month $6: 1.16 \pm 0.02 \mathrm{~g} / \mathrm{cm}^{2}$ ).

In our sub-analysis (Fig. 3B and 3C), weight loss was greater $(P<0.05)$ in ADF postmenopausal women $(-11.2 \pm 2.3 \%)$ versus ADF premenopausal women $(-6.0 \pm 1.1 \%)$. Additionally, weight loss was greater $(P<0.05)$ in $\mathrm{CR}$ postmenopausal women $(-11.6 \pm 3.7 \%)$ versus CR premenopausal women $(-6.0 \pm 1.0 \%)$. Fat mass loss was also greater $(P<0.05)$ in postmenopausal women versus premenopausal women in the ADF and CR groups. Changes in lean mass and bone mineral content did not differ between premenopausal and postmenopausal women in any group. Total body bone mineral density did not differ at month 6 between ADF premenopausal women $\left(1.22 \pm 0.02 \mathrm{~g} / \mathrm{cm}^{2}\right)$ and ADF postmenopausal women $\left(1.21 \pm 0.04 \mathrm{~g} / \mathrm{cm}^{2}\right)$, or between CR premenopausal women $\left(1.24 \pm 0.04 \mathrm{~g} / \mathrm{cm}^{2}\right)$ and $\mathrm{CR}$ postmenopausal women $\left(1.10 \pm 0.04 \mathrm{~g} / \mathrm{cm}^{2}\right)$.

\subsection{Dietary intake and physical activity}

Energy intake decreased $(P<0.01)$ from baseline to month 6 in the ADF and CR groups, but did not change in the control group (Table 2). Percent energy intake from protein, carbohydrates, and fat did not differ significantly between groups or over time. Dietary calcium and vitamin D intake remained constant from baseline to month 6 , and did not differ between groups. Physical activity did not change significantly over the course of the trial in the ADF group (baseline: $8172 \pm 751$ steps/d; month 6:8324 \pm 477 steps/d), CR group (baseline: $6923 \pm 543$ steps/d; month 6:8406 \pm 878 steps/d) and control group (baseline: $6861 \pm 682$ steps/d; month $6: 6467 \pm 363$ steps/d), with no difference between groups at any time point. There were no differences in activity level (steps/d) at baseline or month 6 between premenopausal women versus postmenopausal women in any group.

\subsection{Circulating hormones and markers of bone metabolism}

In the analysis of all participants (Table 3), IGF1 increased in the CR group, but did not change in the ADF or control group. Circulating osteocalcin, bone alkaline phosphatase and CTX did not change over the course of the trial in any group. In our sub-analysis (Table 4), premenopausal and postmenopausal women in the ADF and CR groups did not exhibit any changes in markers of bone formation or resorption after 6 months, relative to controls. There were no differences between premenopausal or postmenopausal women for any marker of bone metabolism. 
Table 2

All participants: Dietary intake at baseline and month 6

\begin{tabular}{|c|c|c|c|c|c|c|c|c|c|}
\hline \multirow[b]{2}{*}{ All participants } & \multicolumn{2}{|c|}{$\begin{array}{c}\text { Alternate day } \\
\text { fasting }(n=21)\end{array}$} & \multicolumn{2}{|c|}{$\begin{array}{c}\text { Daily Calorie } \\
\text { Restriction }(n=24)\end{array}$} & \multicolumn{2}{|c|}{$\begin{array}{l}\text { Control } \\
(n=17)\end{array}$} & \multicolumn{3}{|c|}{$P$-values ${ }^{1}$} \\
\hline & Baseline & 6 Months & Baseline & 6 Months & Baseline & 6 Months & Diet & Time & $\begin{array}{r}\text { Diet } \times \\
\text { Time }\end{array}$ \\
\hline Energy (kcal) & $1744 \pm 208$ & $1500 \pm 164$ & $1927 \pm 118$ & $1771 \pm 153$ & $1617 \pm 118$ & $1589 \pm 99$ & 0.17 & 0.11 & $<0.01^{2}$ \\
\hline Protein $(\% \mathrm{kcal})$ & $18 \pm 3$ & $18 \pm 3$ & $17 \pm 1$ & $17 \pm 1$ & $18 \pm 1$ & $18 \pm 1$ & 0.53 & 0.98 & 0.95 \\
\hline Carbohydrates (\% kcal) & $47 \pm 2$ & $48 \pm 3$ & $49 \pm 1$ & $50 \pm 2$ & $47 \pm 2$ & $46 \pm 3$ & 0.86 & 0.21 & 0.22 \\
\hline Fat $(\% \mathrm{kcal})$ & $35 \pm 1$ & $34 \pm 2$ & $34 \pm 1$ & $33 \pm 1$ & $35 \pm 2$ & $36 \pm 2$ & 0.29 & 0.50 & 0.18 \\
\hline Cholesterol (mg) & $219 \pm 22$ & $232 \pm 39$ & $266 \pm 28$ & $242 \pm 36$ & $278 \pm 28$ & $242 \pm 27$ & 0.76 & 0.27 & 0.97 \\
\hline Fiber $(\mathrm{g})$ & $14 \pm 1$ & $14 \pm 2$ & $17 \pm 1$ & $20 \pm 2$ & $15 \pm 2$ & $12 \pm 1$ & 0.54 & 0.13 & 0.56 \\
\hline Calcium $(\mathrm{mg})^{3}$ & $777 \pm 88$ & $521 \pm 80$ & $662 \pm 42$ & $744 \pm 68$ & $592 \pm 55$ & $593 \pm 67$ & 0.98 & 0.87 & 0.93 \\
\hline Vitamin D (ug) ${ }^{3}$ & $4 \pm 1$ & $3 \pm 1$ & $3 \pm 1$ & $3 \pm 1$ & $3 \pm 1$ & $3 \pm 1$ & 0.88 & 0.99 & 0.94 \\
\hline
\end{tabular}

Mean \pm SEM. ${ }^{1}$ Repeated measures ANOVA. ${ }^{2}$ Energy intake decreased in the ADF and CR group, with no change in the control group.

${ }^{3}$ Estimated from dietary intake alone. Calcium and Vitamin D supplements were permitted during the study, but were not recorded in the food records.

Table 3

All participants: Change in markers of bone metabolism after 6 months

\begin{tabular}{|c|c|c|c|c|c|c|c|c|c|}
\hline \multirow[b]{2}{*}{ All participants } & \multicolumn{2}{|c|}{$\begin{array}{c}\text { Alternate day } \\
\text { fasting }(n=21)\end{array}$} & \multicolumn{2}{|c|}{$\begin{array}{c}\text { Daily Calorie } \\
\text { Restriction }(n=24)\end{array}$} & \multicolumn{2}{|c|}{$\begin{array}{l}\text { Control } \\
(n=17)\end{array}$} & \multicolumn{3}{|c|}{$P$-values ${ }^{1}$} \\
\hline & Baseline & 6 Months & Baseline & 6 Months & Baseline & 6 Months & Diet & Time & $\begin{array}{r}\text { Diet } \times \\
\text { Time }\end{array}$ \\
\hline Osteocalcin (ng/ml) & $12 \pm 2$ & $13 \pm 3$ & $14 \pm 5$ & $19 \pm 5$ & $18 \pm 4$ & $19 \pm 6$ & 0.22 & 0.14 & 0.87 \\
\hline Bone ALP (U/L) & $5 \pm 1$ & $6 \pm 2$ & $6 \pm 1$ & $4 \pm 1$ & $5 \pm 2$ & $4 \pm 2$ & 0.99 & 0.09 & 0.18 \\
\hline IGF-1 (ng/ml) & $87 \pm 6$ & $88 \pm 6$ & $106 \pm 8$ & $119 \pm 11$ & $110 \pm 12$ & $92 \pm 9$ & 0.15 & 0.43 & $<0.01^{2}$ \\
\hline CTX (ng/ml) & $0.6 \pm 0.1$ & $0.8 \pm 0.2$ & $1.3 \pm 0.2$ & $1.3 \pm 0.2$ & $1.5 \pm 0.3$ & $1.4 \pm 0.2$ & 0.33 & 0.36 & 0.68 \\
\hline
\end{tabular}

Mean \pm SEM. Bone ALP: Bone alkaline phosphatase, CTX: C-terminal telopeptide of type I collagen, IGF-1: Insulin-like growth factor-1.

${ }^{1}$ Repeated measures ANOVA. ${ }^{2}$ IGF-1 increased in the CR group, with no change in the ADF or control group.

Table 4

Premenopausal and postmenopausal women: Change in markers of bone metabolism after 6 months

\begin{tabular}{|c|c|c|c|c|c|c|c|c|c|}
\hline & \multicolumn{2}{|c|}{$\begin{array}{l}\text { Alternate day } \\
\text { fasting }\end{array}$} & \multicolumn{2}{|c|}{$\begin{array}{c}\text { Daily Calorie } \\
\text { Restriction }\end{array}$} & \multicolumn{2}{|c|}{ Control } & \multicolumn{3}{|c|}{$P$-values ${ }^{1}$} \\
\hline & Baseline & 6 Months & Baseline & 6 Months & Baseline & 6 Months & Diet & Time & $\begin{array}{r}\text { Diet } \times \\
\text { Time }\end{array}$ \\
\hline \multicolumn{10}{|l|}{ Premenopausal } \\
\hline Osteocalcin (ng/ml) & $11 \pm 2$ & $11 \pm 1$ & $9 \pm 2$ & $11 \pm 2$ & $20 \pm 7$ & $19 \pm 9$ & 0.34 & 0.64 & 0.42 \\
\hline Bone ALP (U/L) & $4 \pm 1$ & $7 \pm 2$ & $5 \pm 2$ & $4 \pm 1$ & $6 \pm 2$ & $6 \pm 2$ & 0.63 & 0.71 & 0.17 \\
\hline IGF-1 (ng/ml) & $85 \pm 6$ & $90 \pm 7$ & $105 \pm 12$ & $132 \pm 19$ & $118 \pm 17$ & $106 \pm 13$ & 0.25 & 0.35 & 0.10 \\
\hline CTX (ng/ml) & $0.6 \pm 0.1$ & $0.6 \pm 0.2$ & $0.8 \pm 0.1$ & $0.6 \pm 0.1$ & $1.2 \pm 0.3$ & $1.2 \pm 0.2$ & 0.17 & 0.46 & 0.33 \\
\hline \multicolumn{10}{|l|}{ Postmenopausal } \\
\hline Osteocalcin (ng/ml) & $12 \pm 5$ & $18 \pm 10$ & $12 \pm 4$ & $14 \pm 4$ & $11 \pm 2$ & $13 \pm 4$ & 0.14 & 0.60 & 0.83 \\
\hline Bone ALP (U/L) & $7 \pm 4$ & $6 \pm 4$ & $6 \pm 2$ & $5 \pm 2$ & $4 \pm 2$ & $4 \pm 1$ & 0.38 & 0.20 & 0.62 \\
\hline IGF-1 (ng/ml) & $79 \pm 15$ & $79 \pm 14$ & $110 \pm 19$ & $95 \pm 11$ & $107 \pm 36$ & $100 \pm 38$ & 0.91 & 0.47 & 0.28 \\
\hline CTX (ng/ml) & $1.5 \pm 0.6$ & $1.1 \pm 0.3$ & $1.8 \pm 0.6$ & $1.6 \pm 0.4$ & $2.4 \pm 0.9$ & $2.3 \pm 0.7$ & 0.57 & 0.35 & 0.81 \\
\hline
\end{tabular}

Mean \pm SEM. Bone ALP: Bone alkaline phosphatase, CTX: C-terminal telopeptide of type I collagen, IGF-1: Insulin-like growth factor-1.

${ }^{1}$ Repeated measures ANOVA.

\section{Discussion}

This is the first study to examine the impact of ADF on markers of bone metabolism. We show here that 6 months of ADF has no effect on markers of bone formation (osteocalcin, bone alkaline phosphatase) or bone resorption (CTX) when compared to daily CR or weight stable controls. We also demonstrate that total body bone mineral density and content remain stable after 6 months of ADF. In our sub-analysis of premenopausal versus postmenopausal women, it was shown that $\mathrm{ADF}$ has no impact on markers of 
bone metabolism or total body bone mineral content or density in either of these groups of women.

The bone formation marker, osteocalcin, remained stable in our analysis of all participants, and also in our sub-analysis of premenopausal versus postmenopausal women. Previous studies of CR generally demonstrate no change in osteocalcin levels after 6 months $[11,19,20]$. In the few studies that have specifically examined premenopausal versus postmenopausal women, osteocalcin levels have also been shown to remain unaffected $[11,19,20]$. The lack of change in osteocalcin may partly explain why total body bone mineral density and content remained stable in the intervention groups. It is also possible that bone mineral content and density did not change because subjects in the present trial were more physically active than the average obese American. More specifically, their activity level was 1000-2000 steps/d higher than what has been reported [26]. Since higher levels of physical activity can help preserve bone mass [27, 28], this could explain why bone mineral density and content remained stable in the present study.

Neither ADF nor CR affected circulating levels of bone alkaline phosphatase, a marker of bone formation. This parameter also remained stable in our sub-analysis of premenopausal and postmenopausal women. We are aware of only one other trial of similar duration that examined the impact of dietary restriction on bone alkaline phosphatase. In this study by Redman et al. [17], 6 months of CR decreased body weight by $10 \%$ and bone alkaline phosphatase by $16 \%$ in overweight young men and premenopausal women. Our findings showed a statistically insignificant $44 \%$ decline in bone alkaline phosphatase in the CR group, even though we had double the number of treated subjects. However, subjects in the Redman study [17] were excluded if they were obese or if they ever had a history of obesity. Given that the bone response to weight loss is greater in leaner versus heavier individuals [29], this could explain differences in findings between these studies.

Circulating levels of the bone resorption marker, CTX, did not change in the ADF or CR groups after 6 months of treatment. Our findings for CTX are contradictory to previous 6-month controlled trials of $\mathrm{CR}$, which show that CTX and other markers of bone resorption increase in response to moderate weight loss $[14,15,17,30]$. Levels of CTX also remained unchanged in premenopausal and postmenopausal women undergoing ADF or CR. These preliminary findings suggest that $\mathrm{ADF}$ may not increase bone resorption with moderate weight loss, though it is not known whether a longer duration of ADF would have a different effect.

IGF-1 is a critical mediator of bone growth [31]. In the present study, we found that IGF-1 levels remained stable in the ADF group, but increased in the CR group. Some CR trials report decreases in IGF-1 levels after 6-12 months [32, 33], though others show no change $[14,15,34]$. Since IGF-1 helps promote bone growth [31], increased levels of this mediator may positively affect bone long-term. It remains uncertain why IGF-1 levels were not affected by $\mathrm{ADF}$, as average energy restriction and weight loss was similar to that of the CR group. Harvie at al [35] also reported no change in IGF-1 concentrations after 6 months of intermittent fasting in obese premenopausal women. Higher protein intakes increase IGF-1 which may indirectly help to preserve bone mass [36]. However, average protein intake over the course of the trial was similar in the ADF and CR groups ( $\sim 18 \%$ of energy), thus it is unlikely that this factor played a role. While this finding may suggest that CR has a protective effect on bone versus $\mathrm{ADF}$, we found no differences in bone changes, suggesting that more research is required before solid conclusions can be reached.

Dietary intakes of calcium and vitamin D were below the recommended intakes of $1000-1200 \mathrm{mg}$ $\mathrm{Ca} / \mathrm{d}$ and $15 \mathrm{ug}$ vitamin $\mathrm{D} / \mathrm{d}$ for men and women in this age group. However, intakes reported in this study were similar to the average intake for US women $(\sim 850 \mathrm{mg} / \mathrm{d}$ for calcium and $4 \mu \mathrm{g} / \mathrm{d}$ for vitamin D) and men $(\sim 1100 \mathrm{mg} / \mathrm{d}$ for calcium and $5 \mu \mathrm{g} / \mathrm{d}$ for vitamin D) [25].

Our study has some limitations. First, this is a secondary analysis of a larger study [21] which focused primarily on changes in body weight with these diets. Thus, our study may not have been powered adequately to detect differences between $\mathrm{ADF}, \mathrm{CR}$, and controls for changes in markers of bone metabolism. However, other studies found changes in bone markers with weight loss with smaller sample sizes $[16,17$, 30]. Second, the study was not designed to examine whether these diets have any impact on site-specific bone mineral density (e.g. hip, lumbar spine, etc.).

In summary, these findings suggest that moderate weight loss with ADF does not have any deleterious impact on markers of bone metabolism or total body bone mineral density in obese adults. A future ADF randomized controlled trial designed to measure bone at multiple high-risk fracture sites is needed to confirm these findings. 


\section{Acknowledgments}

$\mathrm{AB}$ preformed the laboratory analyses, analyzed the data, and wrote the manuscript. CMK, JFT, MCK, SB, KKH, KG coordinated the clinical trial, and assisted with manuscript preparation. SAS assisted with interpretation of the data and wrote the manuscript. KAV designed the experiment, analyzed the data, and wrote the manuscript.

\section{Funding source}

National Institutes of Health: NHLBI (R01HL 106228, T32HL007034), NIDDK (F32DK107157).

\section{Conflict of interest}

Krista Varady is the author of the book, "The Every Other Day Diet". The other authors have no competing interests.

\section{References}

[1] Fock KM, Khoo J. Diet and exercise in management of obesity and overweight. Journal of Gastroenterology and Hepatology. 2013;28(Suppl 4):59-63.

[2] Davis CS, Clarke RE, Coulter SN, et al. Intermittent energy restriction and weight loss: A systematic review. European Journal of Clinical Nutrition. 2015.

[3] Keogh JB, Pedersen E, Petersen KS, Clifton PM. Effects of intermittent compared to continuous energy restriction on short-term weight loss and long-term weight loss maintenance. Clinical Obesity. 2014;4(3):150-6.

[4] Bhutani S, Klempel MC, Kroeger CM, Trepanowski JF, Varady KA. Alternate day fasting and endurance exercise combine to reduce body weight and favorably alter plasma lipids in obese humans. Obesity. 2013;21(7):1370-9.

[5] Eshghinia S, Mohammadzadeh F. The effects of modified alternate-day fasting diet on weight loss and CAD risk factors in overweight and obese women. Journal of Diabetes and Metabolic Disorders. 2013;12(1):4.

[6] Hoddy KK, Kroeger CM, Trepanowski JF, Barnosky A, Bhutani S, Varady KA. Meal timing during alternate day fasting: Impact on body weight and cardiovascular disease risk in obese adults. Obesity. 2014;22(12):2524-31.

[7] Johnson JB, Summer W, Cutler RG, et al. Alternate day calorie restriction improves clinical findings and reduces markers of oxidative stress and inflammation in overweight adults with moderate asthma. Free Radic Biol Med. 2007;42(5):665-74.

[8] Klempel MC, Kroeger CM, Varady KA. Alternate day fasting (ADF) with a high-fat diet produces similar weight loss and cardio-protection as ADF with a low-fat diet. Metabolism: Clinical and Experimental. 2013;62(1):137-43.

[9] Varady KA, Bhutani S, Church EC, Klempel MC. Short-term modified alternate-day fasting: A novel dietary strategy for weight loss and cardioprotection in obese adults. Am J Clin Nutr. 2009;90(5):1138-43.

[10] Catenacci VA, Pan Z, Ostendorf D, et al. A randomized pilot study comparing zero-calorie alternate-day fasting to daily caloric restriction in adults with obesity. Obesity. 2016;24(9):1874-83.

[11] Zibellini J, Seimon RV, Lee CM, et al. Does diet-induced weight loss lead to bone loss in overweight or obese adults? A systematic review and meta-analysis of clinical trials. Journal of Bone and Mineral Research: The Official Journal of the American Society for Bone and Mineral Research. 2015;30(12):2168-78.

[12] Huang TH, Ables GP. Dietary restrictions, bone density, and bone quality. Annals of the New York Academy of Sciences. 2016.

[13] Villareal DT, Kotyk JJ, Armamento-Villareal RC, et al. Reduced bone mineral density is not associated with significantly reduced bone quality in men and women practicing long-term calorie restriction with adequate nutrition. Aging Cell. 2011;10(1):96-102.

[14] Villareal DT, Shah K, Banks MR, Sinacore DR, Klein S. Effect of weight loss and exercise therapy on bone metabolism and mass in obese older adults: A oneyear randomized controlled trial. The Journal of Clinical Endocrinology and Metabolism. 2008;93(6):2181-7.

[15] Villareal DT, Fontana L, Das SK, et al. Effect of two-year caloric restriction on bone metabolism and bone mineral density in non-obese younger adults: A randomized clinical trial. Journal of Bone and Mineral Research: The Official Journal of the American Society for Bone and Mineral Research. 2016;31(1):40-1.

[16] Riedt CS, Cifuentes M, Stahl T, Chowdhury HA, Schlussel Y, Shapses SA. Overweight postmenopausal women lose bone with moderate weight reduction and $1 \mathrm{~g} /$ day calcium intake. Journal of Bone and Mineral Research: The Official Journal of the American Society for Bone and Mineral Research. 2005;20(3):455-63.

[17] Redman LM, Rood J, Anton SD, et al. Calorie restriction and bone health in young, overweight individuals. Archives of Internal Medicine. 2008;168(17):1859-66.

[18] Pop LC, Sukumar D, Tomaino K, et al. Moderate weight loss in obese and overweight men preserves bone quality. Am J Clin Nutr. 2015;101(3):659-67.

[19] Riedt CS, Schlussel Y, von Thun N, et al. Premenopausal overweight women do not lose bone during moderate weight loss with adequate or higher calcium intake. Am J Clin Nutr. 2007;85(4):972-80.

[20] Shapses SA, Von Thun NL, Heymsfield SB, et al. Bone turnover and density in obese premenopausal women during moderate weight loss and calcium supplementation. Journal of Bone and Mineral Research: The Official Journal of the American Society for Bone and Mineral Research. 2001;16(7):1329-36.

[21] Trepanowski JF, Kroeger CM, Barnosky A, et al. Effect of alternate-day fasting on weight loss, weight maintenance, and cardioprotection among metabolically healthy obese adults: A randomized clinical trial. JAMA Intern Med. 2017.

[22] Gidding SS, Lichtenstein AH, Faith MS, et al. Implementing American Heart Association pediatric and adult nutrition guidelines: A scientific statement from the American Heart Association Nutrition Committee of the Council on Nutrition, Physical Activity and Metabolism, Council on 
Cardiovascular Disease in the Young, Council on Arteriosclerosis, Thrombosis and Vascular Biology, Council on Cardiovascular Nursing, Council on Epidemiology and Prevention, and Council for High Blood Pressure Research. Circulation. 2009;119(8):1161-75.

[23] Schoeller DA. Measurement of energy expenditure in freeliving humans by using doubly labeled water. The Journal of Nutrition. 1988;118(11):1278-89.

[24] Johannsen DL, Calabro MA, Stewart J, Franke W, Rood JC, Welk GJ. Accuracy of armband monitors for measuring daily energy expenditure in healthy adults. Medicine and Science in Sports and Exercise. 2010;42(11):2134-40.

[25] Bailey RL, Dodd KW, Goldman JA, et al. Estimation of total usual calcium and vitamin D intakes in the United States. The Journal of Nutrition. 2010;140(4):817-22.

[26] Tudor-Locke C, Brashear MM, Johnson WD, Katzmarzyk PT. Accelerometer profiles of physical activity and inactivity in normal weight, overweight, and obese U.S. men and women. The International Journal of Behavioral Nutrition and Physical Activity. 2010;7:60.

[27] Muir JM, Ye C, Bhandari M, Adachi JD, Thabane L. The effect of regular physical activity on bone mineral density in post-menopausal women aged 75 and over: A retrospective analysis from the Canadian multicentre osteoporosis study. BMC Musculoskeletal Disorders. 2013;14:253.

[28] Wolff I, van Croonenborg JJ, Kemper HC, Kostense PJ, Twisk JW. The effect of exercise training programs on bone mass: A meta-analysis of published controlled trials in pre- and postmenopausal women. Osteoporosis International: A Journal Established as Result of Cooperation between the European Foundation for Osteoporosis and the National Osteoporosis Foundation of the USA. 1999;9(1):1-12.
[29] Nguyen TV, Sambrook PN, Eisman JA. Bone loss, physical activity, and weight change in elderly women: The Dubbo Osteoporosis Epidemiology Study. Journal of Bone and Mineral Research: The Official Journal of the American Society for Bone and Mineral Research. 1998;13(9):1458-67.

[30] Ricci TA, Heymsfield SB, Pierson RN Jr, Stahl T, Chowdhury HA, Shapses SA. Moderate energy restriction increases bone resorption in obese postmenopausal women. Am J Clin Nutr. 2001;73(2):347-52.

[31] Guntur AR, Rosen CJ. IGF-1 regulation of key signaling pathways in bone. BoneKEy Reports. 2013;2:437.

[32] Fontana L, Villareal DT, Das SK, et al. Effects of 2-year calorie restriction on circulating levels of IGF-1, IGF-binding proteins and cortisol in nonobese men and women: A randomized clinical trial. Aging Cell. 2016;15(1):22-7.

[33] Fontana L, Weiss EP, Villareal DT, Klein S, Holloszy JO. Long-term effects of calorie or protein restriction on serum IGF-1 and IGFBP-3 concentration in humans. Aging Cell. 2008;7(5):681-7.

[34] Redman LM, Veldhuis JD, Rood J, et al. The effect of caloric restriction interventions on growth hormone secretion in nonobese men and women. Aging Cell. 2010;9(1):32-9.

[35] Harvie MN, Pegington M, Mattson MP, et al. The effects of intermittent or continuous energy restriction on weight loss and metabolic disease risk markers: A randomized trial in young overweight women. International Journal of Obesity. 2011;35(5):714-27.

[36] Heaney RP, Layman DK. Amount and type of protein influences bone health. Am J Clin Nutr. 2008;87(5):1567S-70S. 